\title{
The Integrated Programme for Commodities: an Assessment of Progress and Prospects
}

\section{l. S. Chadha}

The issue of commodities and the Common Fund (CF) was the major theme of the fourth session of UNCTAD in Nairobi in 1976. The slow progress of negotiations under the Integrated Programme for Commodities (IPC) launched at that session, and particularly the continuing stalemate in the protracted negotiations on the CF, gave rise to fears on the eve of UNCTAD $V$ that the issue might once again dominate the discussion and the resulting acrimonious debate detract from other urgent issues. Happily, this prospect receded after the successful negotiations on the CF in March 1979. With its fundamental elements already agreed (UNCTAD 1979, Annex I) and the process of the drafting of its Articles of Agreement set in motion, discussions in Manila on the subject of commodities could concentrate on a review of the progress of work on individual commodities and on certain developmental aspects of commodity policy which had not received enough attention in the past. A number of governments also took the opportunity to announce their intention to make voluntary contributions to the second window of the CF.

The agreement on the fundamental elements of the $C F$, which is seen as a key instrument for attaining the agreed objectives of the IPC, will, it is hoped, provide a much needed impetus to the IPC as a whole. An Interim Committee has been established to draft the Articles of Agreement of the Fund. This is expected to be completed by the end of 1979; the Negotiating Conference would then be convened to adopt the Articles of Agreement.

\section{The Two Windows}

The CF's first window will help finance international buffer stocks and internationally coordinated national stocks, within the framework of international commodity agreements and arrangements (ICAs). Its second window will finance measures other than stocking, and promote coordination and consultation on such measures, including research and development, productivity improvement, marketing and assistance in diversification. Such measures will have to be jointly sponsored and followed up by pro- ducers and consumers within the framework of international commodity bodies meeting agreed criteria. Provision has been made for a close working relationship with existing international financial institutions and for any duplication of their activities to be avoided as far as possible. It is envisaged that the second window may undertake co-financing of some projects, in association with other bodies.

The financial structure of the Fund envisages direct government contributions to its capital of $\$ 470 \mathrm{mn}$. The amount to be allocated to the first window is to be $\$ 400 \mathrm{mn}$, of which $\$ 150 \mathrm{mn}$ is to be contributed in cash at the establishment of the Fund, $\$ 150 \mathrm{mn}$ as capital on call to be paid in as and when needed by the Fund for its operations, and $\$ 100 \mathrm{mn}$ as callable capital to back the Fund's borrowing.

The formula for the apportionment of direct government contributions among the member states provides for a contribution of $\$ 1 \mathrm{mn}$ by each member state of which a part may be allocated by the contributing state to the second window so that the amount so allocated would be not less than $\$ 70 \mathrm{mn}$. This represents a compromise between the developed countries' view that the resources of the second window should be derived entirely from voluntary contributions, and the insistence by the Group of 77 that a part of the capital of the Fund should be allocated to the second window. Assuming that 150 countries will join the Fund, this would leave a balance of $\$ 80$ $\mathrm{mn}$ for the first window. The remaining $\$ 320 \mathrm{mn}$ for the first window would be apportioned among the Groups on the basis of 10 per cent for the Group of 77, 68 per cent for Group B (developed market-economy countries), 17 per cent for Group D (socialist countries of Eastern Europe) and 5 per cent for China. Provision has been made for voluntary contributions to the second window, for which a target of $\$ 280 \mathrm{mn}$ has been set, and for the periodic replenishment of its resources.

ICAs to be associated with the Fund would be required to deposit with it one-third of their maximum financial requirements and would be entitled to borrow the remaining two-thirds from the Fund against pledges of callable capital of 
equivalent amount by the participants of the ICAs. For this purpose the Fund would be authorised to raise resources through borrowing. The ICAs would be entitled to withdraw their cash deposits whenever they were needed for stock purchases and would be required to assign their stock warrants to the Fund. An important advance made during the negotiations was the acceptance of the principle of joint financing of stocks within ICAs by producers and consumers.

Votes would be allocated among the members of the Fund so as to secure 47 per cent for the Group of 77, 42 per cent for Group B, 8 per cent for Group D and 3 per cent for China. Decisions would be taken, wherever possible, without a vote. The most important decisions, including constitutional ones and those with significant financial implications for member states, would be taken on the basis of a majority of 75 per cent of total votes cast. Other decisions, according to their relative importance, would be subject to a two-thirds or simple majority.

Although the agreement on the fundamental elements of the CF was approved by consensus, a number of reservations were subsequently made. Group D expressed reservations about the formula for the apportionment of direct government contributions among the various groups, particularly the provision for the contribution of $\$ 1 \mathrm{mn}$ by each member, the distribution of votes, and the provision on the joint financing of ICAs. The United States could not accept the formula for the distribution of votes because it felt that there should be parity between Group $B$ and the Group of 77. Statements were also made by a number of developing countries which were disappointed with the results and would have wished particularly to see improvements in the scope and resources of the second window.

\section{Areas of Advance}

The CF will be a significant innovation in international institutions concerned with economic cooperation. Whereas developing countries have only a peripheral role in some existing institutions, in the CF they will be equal partners with developed countries. They will provide a sizeable portion of the Fund's resources and have a strong voice in the process of decision making. But the innovative character of the Fund will not be confined to the greater participation of developing countries in its financial and management structures. Of even greater significance is the fact that it is intended to be an international cooperative endeavour which will take into account the interests of all countries. Its operations are designed to provide substantial benefits for both developing and developed countries.

The CF should play an important role in providing greater stability and strength to the international markets for commodities of export interest to developing countries. By providing finance on attractive terms for the support of prices through ICAs, it will be able to act as a catalyst in bringing about such agreements. The participants in ICAs will in the future need to raise only one-third of the finance in cash. They will then have the assurance of securing the balance from the Fund on reasonable terms. This should be a crucial factor in the success of negotiations on individual commodities. Given the agreement on joint financing by producers and consumers, producing countries, most of which are poor developing countries, will have to provide in cash only one-sixth of the total financial requirements. This contrasts with the past requirement for producers to provide 100 per cent of the mandatory contributions while contributions by the consumers were voluntary.

The CF will also make a significant contribution to the economic development of developing countries through financial assistance from its second window for measures other than stocking which have hitherto received inadequate attention. The establishment of the second window will increase the relevance of the $C F$ for a large number of developing countries, particularly the relatively poor among them who might not readily benefit from stocking operations.

In assessing the adequacy of the financial structure of the CF, a comparison is sometimes made between the size of direct government contributions to be allocated to the first window, and the capital structure envisaged in the original proposals of the UNCTAD Secretariat. It may be recalled that these proposals were based on an estimate of $\$ 6$ bn for the financial requirements of stocking the 10 'core' commodities, of which one-third ( $\$ 2 \mathrm{bn}$ ) was to be provided by the members of the Fund and the remaining twothirds ( $\$ 4 \mathrm{bn}$ ) was to be raised through borrowing. It would not be correct, in assessing whether the resources of the Fund will be adequate to meet the requirements of ICAs, to compare these figures with the amount of $\$ 400 \mathrm{mn}$ to be allocated to the first window from direct government contributions. Such a comparison can be quite misleading because the financial structure now envisaged for the Fund is quite different from 
that originally contemplated. There is still a provision for one-third of the financial requirements of ICAs to be contributed in cash (though this will be done by the participants in ICAs as and when they are concluded and not initially by the members of the Fund) and for borrowing the remaining two-thirds. The Fund will be adequately equipped to meet the entire borrowing needs of the ICAs, regardless of their number and the size of their stocks. In addition to the direct government contributions, which would serve to enhance the Fund's creditworthiness and provide it with the finance needed for operational purposes, administrative costs and liquidity requirements, it will be equipped with a reserve in the form of callable capital to enable it to raise the necessary resources through borrowing.

\section{Next Steps}

There is a great deal of ground still to be covered before the Fund can be brought into operation. It was evident during the negotiations that some elements require further elaboration. These include: the appropriate institutional framework for sponsoring and following up the measures to be financed by the second window; the determination of the formula for the apportionment of assessed contributions among individual countries within the various groups; the operating principles of the CF and its relationship with ICAs (particularly the modalities and conditions for pledging and calling up callable capital to be provided by ICA members); and the actual distribution of votes among individual countries. The complexity of the task of preparing the legal texts of the Articles of Agreement should also not be underestimated. As noted earlier, the concept of the CF is a major innovation amongst international financial institutions. The provisions with regard to the capital structure of the Fund, its operational principles and its relationship with ICAs involve complex legal and technical issues for which there are no precedents.

Closely related to the process of the establishment of the CF is the need to make more rapid progress in the negotiations for concluding new ICAs. Such progress is necessary if the Fund is to be in a position to start its operations on a wide front as a truly effective instrument for the attainment of the objectives of the IPC. As pointed out in a comprehensive review presented by the Secretariat to UNCTAD V (UNCTAD 1979a), the results achieved so far in discussions on individual commodities, whilst not insignificant, cannot be considered adequate either in the light of the original expectations or in terms of the needs and requirements of developing countries.

The ten 'core' commodities originally identified by the UNCTAD Secretariat as being of export interest to developing countries, suitable for stocking, and possible candidates for assistance from the CF, were cocoa, coffee, copper, cotton, hard fibres, jute, rubber, sugar, tea and tin. Four of these-cocoa, coffee, sugar and tin-were already covered by ICAs before the adoption of the IPC, although for various reasons these agreements did not go far enough to solve the problems facing the commodities. Since the adoption of the Programme, the Sugar Agreement has been renegotiated. It has not been very effective so far because the EEC has stayed out of the Agreement and ratification by the United States is still awaited. The economic clauses of the Cocoa Agreement, which is due to expire in September 1979, have remained virtually inoperative as the price ranges incorporated in it have been well below the prevailing market levels throughout its life. Differences between producers and consumers on the question of the price range have been one of the major factors in the lack of progress in the negotiations for the conclusion of a new Agreement which are now under way. The Tin Agreement is the only one which has an operative buffer stock. Even it has not been very effective in recent times in defending the ceiling price because of the small size of its stock. Hitherto the major burden of financing the buffer stock has been borne by the producers. The Coffee Agreement does not have any provision for stocking, and discussions are under way within the Coffee Council for possible modifications in the Agreement.

The efforts to conclude additional ICAs within the framework of the IPC have so far met with only limited success. Despite a large number of preparatory meetings between the producers and consumers of a wide range of commodities, the discussions have advanced to the stage of negotiations for the establishment of an ICA in the case of only one commodity, natural rubber. The Negotiating Conference on natural rubber has held three sessions and agreement has been reached on the main elements of a stabilisation arrangement with provision for a buffer stock. A few details still remain to be worked out but it is expected that an agreement will be concluded soon.

There are good prospects for the early start of negotiations for an international agreement on 


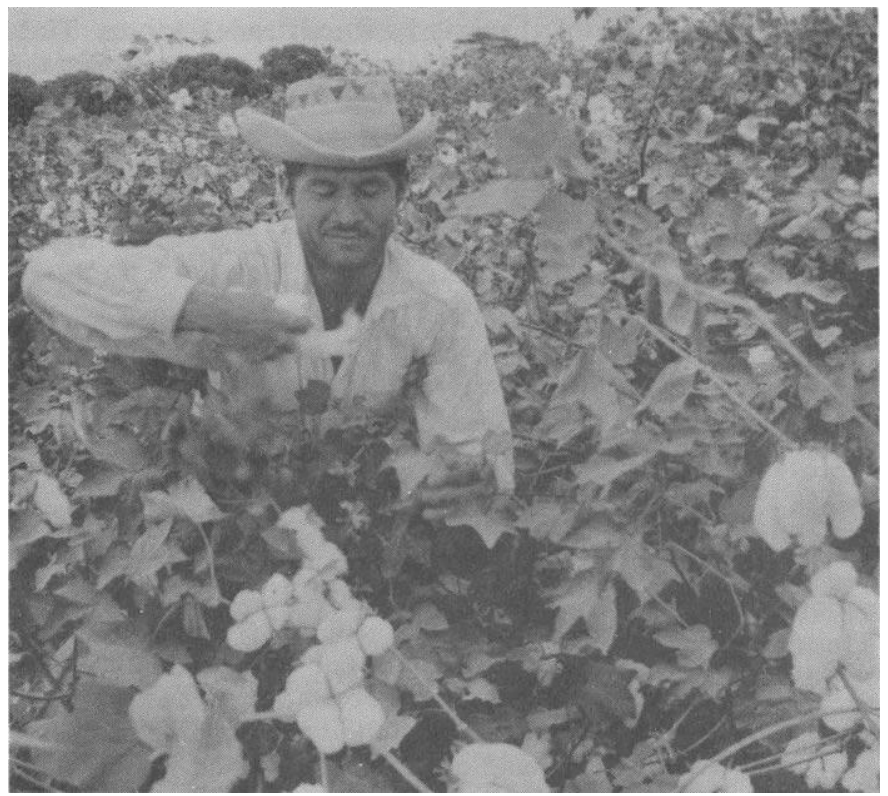

Peter Larsen, Oxfam

Cotton picking in Honduras and Sudan.

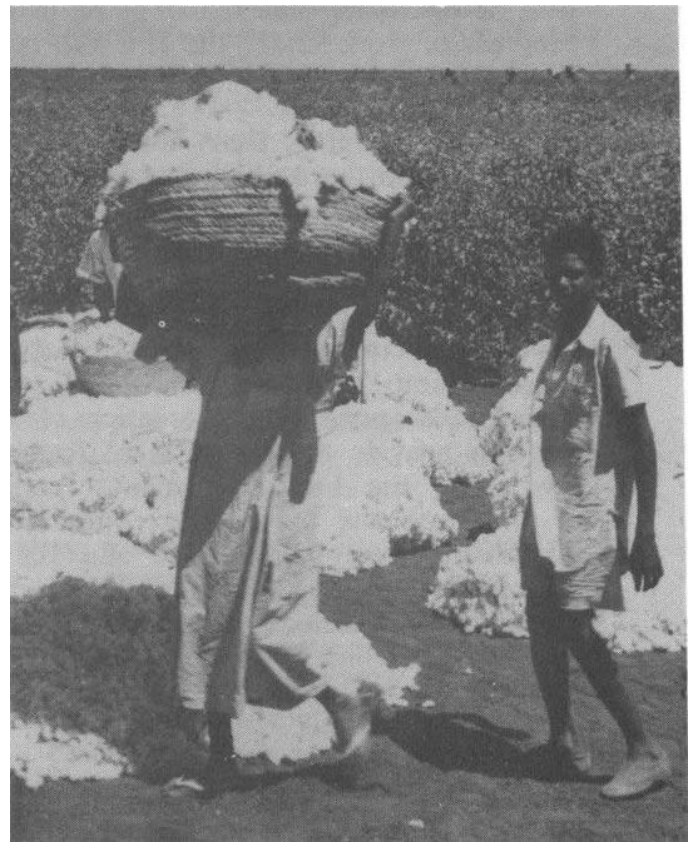

\section{United Nations}

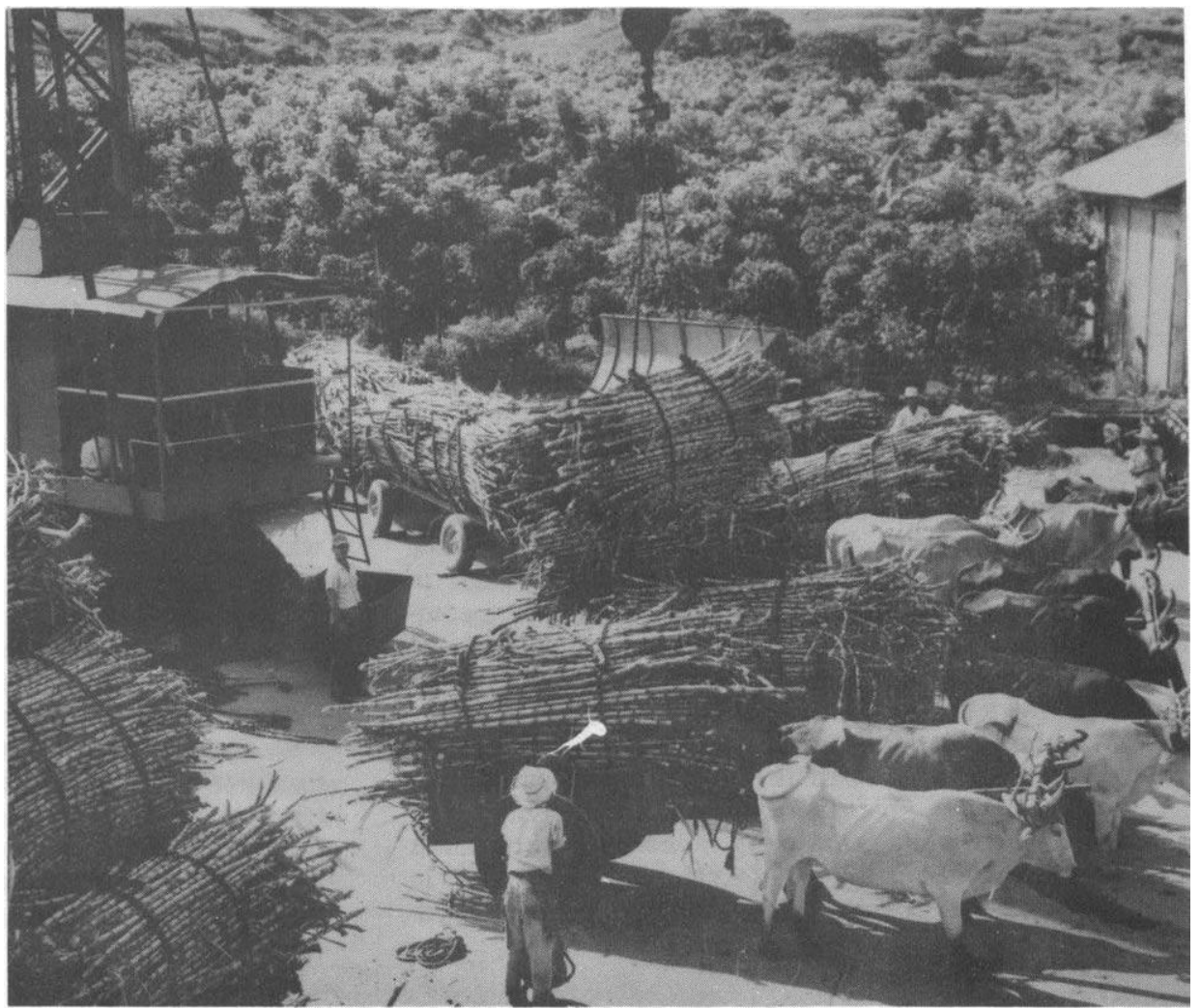


tea. There is general recognition of the need for international measures designed to secure an increase in real export earnings. Although a great deal of discussion has taken place in FAO, the progress of work under the IPC has been slower than anticipated.

For the remaining four 'core' commodities copper, cotton, hard fibres and jute-the preparatory work is fairly well advanced although it has still not reached a stage at which governments are ready to begin negotiations. Numerous intergovernmental meetings have been held on copper which is facing serious problems after a prolonged slump in prices. The earlier discussions were concentrated on the creation of a standing body to provide the institutional framework for continuing the intergovernmental consideration of the problems facing the commodity. These discussions were inconclusive and the focus is now shifting from the institutional issues to more substantive discussions on specific measures to be included in an international agreement. However there has been no significant progress towards starting negotiations.

In the case of cotton, the stage of studying and analysing price fluctuations has been completed. It is expected that further preparatory work will be concentrated on the consideration of specific options relating to price stabilisation and to complementary measures. The discussions have been complicated by the fact that the leading producers are developed countries who have no direct interest in any international action. There have also been differences of approach among producing developing countries.

In the case of jute and hard fibres, both of which face competition from synthetics, considerable progress has been made in the identification of the problems facing the commodities and in drawing up lists of specific measures for research and development and market promotion to improve their competitiveness and to expand their consumption. These measures would no doubt help attain some of the objectives of the Integrated Programme; but they do not go far enough in solving the basic problems facing the commodities and in meeting the requirements of the developing producer countries. Many consuming countries have been reluctant to agree to international action aimed at greater price-stability in jute even though this has been accepted as a specific objective. In recent discussions some consuming countries have been inclined to be more positive on stabilisation measures, but only in respect of raw jute which constitutes a small pro- portion of the international trade in jute. There has also been no agreement on a stabilisation arrangement for sisal and henequen despite clear evidence of instability and notwithstanding a decade-old FAO focus on stabilisation.

\section{Extending the Coverage}

Besides the ten 'core' commodities, UNCTAD Resolution 93 (IV) on the IPC identified another eight commodities of export interest to developing countries (UNCTAD 1979b). These were: bananas, bauxite, iron ore, manganese, meat, phosphates, tropical timber and vegetable oils and oilseeds. Of these commodities, the only one on which significant progress has been made under the IPC is tropical timber. A broad understanding has been reached on some of the possible elements that could be considered as a basis for an international arrangement. These include processing, reforestation, forest management and research and development. However, agreement has not yet been reached in a number of areas, including those relating to market fluctuations.

Discussions on meat were not actively pursued under the Integrated Programme, pending the conclusion of the MTN under GATT. The main outcome of these negotiations was the establishment of an International Meat Council with a largely consultative role. The results fall substantially short of meeting the original objectives of exporting countries, particularly the developing countries, including greater market stability and improved access to markets. These objectives will now be pursued within the framework of the IPC. The discussions on vegetable oils have not made much progress mainly because of major constraints on the adoption of stabilisation measures. These derive from the complexity of problems facing a wide variety of competing products. No preparatory meetings have been held so far on bauxite and bananas.

Unlike many of the agricultural commodities, which have been the subject of consideration in FAO for a number of years, there has been very little international discussion on minerals prior to the preparatory meetings under the IPC. It has therefore been necessary to collect information and data and to undertake technical studies and analysis of the problems facing the commodities before giving consideration to the type of international measures required. A further complication is that in the case of some minerals, developed countries are also major producers. In some cases, such as manganese and phosphates, 
the major developing producer countries have not shown sufficient interest in pursuing the discussions, although these commodities are facing problems which call for international action.

\section{Some Obstacles}

Several factors have inhibited progress in the discussions on individual commodities. The complexity of the issues in the negotiations and the basic conflicts which they seek to resolve should not be underestimated. However, it must be recognised that the resolution of these conflicts would be in the mutual interest of all countries, both producers and consumers, whether developed or developing. There have been repeated affirmations at the highest political level of the importance which governments attach to international action aimed at improving the position of developing countries in world commodity tracie. However, these general pronouncements have not yet been fully reflected in the attitudes of many governments in the continuing negotiations.

A major obstacle encountered in the preparatory work has been the reluctance of many governments to match their commitment to the objectives of the Integrated Programme with a willingness to consider international action aimed at the attainment of these objectives. One of the fundamental objectives of the Programme is to provide greater stability and strength to commodity markets. In most cases this requires some form of international action such as the establishment of buffer stocks and the adoption of other appropriate measures in the framework of international arrangements negotiated between the producers and consumers of the commodities concerned. Despite the acceptance of this objective, many countries are still reluctant to agree to begin negotiations for international arrangements. If the goals which governments have set for themselves are to be attained, this reluctance will have to be overcome. They will need to accept commodity agreements as an essential instrument of international commodity policy.

The attitude of many governments is still dominated by the traditional case-by-case approach based on an assessment of their narrow self-interest in individual commodities, without account being taken of the total benefits for both developing and developed countries which would accrue from the implementation of the IPC as a whole. If the 'integrated' nature of the Programme is to be preserved, consideration will need to be given to governments assuming acrossthe-board commitments within a specified timeframe. This might produce a better balance in the benefits to be derived by individual countries than would be the case if such commitments continue to be sought within the framework of discussions on each individual commodity.

\section{Action at UNCTAD V}

After reviewing the progress of work on individual commodities, UNCTAD $\mathrm{V}$ adopted a resolution calling for early decisions on the convening of negotiating conferences on commodities with proposals now in their preparatory phases but on which sufficient progress had been made, and for the acceleration of preparatory work on other commodities (UNCTAD 1979b, Resolution 124 (V), section $\mathrm{B})$. The resolution highlighted certain specified aspects of the preparatory work and set out guidelines for future action.

Special consideration was given at UNCTAD V to a number of measures envisaged in the IPC which had not so far received adequate attention. These include, for example, the improvement and enlargement of facilities for the stabilisation of the export earnings of developed countries. In a document presented to UNCTAD V (UNCTAD 1979c), the UNCTAD Secretariat analysed shortcomings in the existing facilities and put forward proposals for a complementary facility for commodity-related shortfalls in export earnings. The Conference adopted a resolution requesting the Secretary General of UNCTAD to prepare a detailed study for the operation of such a facility (UNCTAD 1979b, Resolution 125 (V)). As described in Weston's article, the resolution was opposed by most of the developed countries who argued that consideration was being given within the IMF to possible improvements in its Compensatory Financing Facility and the outcome should be awaited before the matter was pursued.

In addition to the stabilisation of commodity prices and the export earnings of developing countries, additional consideration needs to be given to measures which are more developmental in character and which are designed to ensure the full and equitable participation of developing countries in the world commodity economy in areas such as processing, transport, and marketing and distribution of their commodities. This would call for the abolition of a wide variety of discriminatory practices on the part of developed countries which make a significant contribution to the imperfect and inefficient functioning of the world economic system. Some of the measures required are: increased assistance to developing countries for the diversification of production; the expansion of processing; removal of tariff and 
non-tariff barriers to ensure better access to industrial economy markets for the products of developing countries; and improvements in world market structures to ensure a greater participation by developing countries in the transport, marketing and distribution of their products.

The Conference took broad initiatives in these areas (UNCTAD 1979b, Resolution 124 (V), section B). It called for the establishment of frameworks of international cooperation, within the context of the IPC, in the fields of processing, marketing and distribution. It identified the main elements to be taken into account in furthering such cooperation and requested the Secretary General of UNCTAD to undertake detailed studies as a basis of further work. It is hoped that these decisions will lead to concrete international action and make a significant contribution to the economic development of developing countries and to the realisation of the objectives of the IPC.

\section{References}

UNCTAD, 1979, Report of the UN Negotiating Conference on a Common Fund, under the Integrated Programme for Commodities, (TD/ IPC/CF/CONF/19), Geneva

-1979a, Integrated Programme for Commodities: Review of Implementation and Follow-up Action, including the ongoing preparatory work and negotiations, (TD/228), Geneva

-1979b, Resolutions, Recommendations and Decisions Adopted at the Fifth Session, Manila, 7 May-3 June, (CA/1350), Geneva

-1979c, Integrated Programme for Commodities: Action on Earnings Stabilisation and Developmental Aspects of Commodity Policy, (TD/229), Geneva 